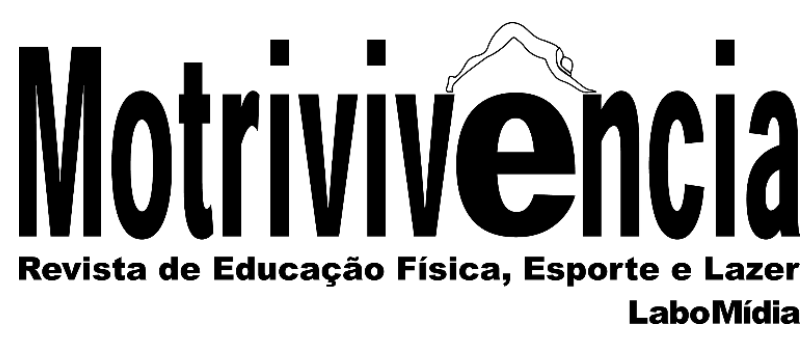

\title{
As teorias da memória na produção científica em Educação Física: uma análise em periódicos brasileiros
}

\section{RESUMO}

O estudo analisa como as concepções de Memória surgem nas produções científicas da Educação Física em periódicos brasileiros publicados no portal de periódicos da Capes. Para isso, foram selecionadas produções acadêmicas publicadas em periódicos indexados, entre os anos de 2013 a 2019, com qualificação Qualis Capes entre A1 e B2. Foram analisados 15 artigos, agrupados em categorias conforme os temas tratados nos estudos. Os resultados apresentam as concepções de memória abordadas nas produções, os objetivos, bem como os aspectos metodológicos que foram desenvolvidos. As considerações assinalam a necessidade de ampliar o diálogo entre as teorias da memória e Educação Física, nas produções científicas e intervenções pedagógicas da área.

PALAVRAS-CHAVE: Memória; Educação física; Produção acadêmica

\section{Marlon Messias Santana Cruz}

Doutorando em Memória, Linguagem e Sociedade - Universidade Estadual do

Sudoeste da Bahia - UESB

Universidade do Estado da Bahia, Departamento de Educação - Campus XII,

Guanambi, Bahia, Brasil marlonmessias@hotmail.com http://orcid.org/0000-0001-9618-848X 

journals

\begin{abstract}
The study analyzes how the conceptions of Memory emerge in the scientific productions of Physical Education in Brazilian journals published in the portal of Capes journals. For this, academic productions published in indexed journals, between the years 2013 to 2019, with Qualis Capes qualification between A1 and B2 were selected. Fifteen articles were analyzed, grouped into categories according to the themes covered in the studies. The results present the conceptions of memory addressed in the productions, the objectives, as well as the methodological aspects that were developed. The considerations point to the need to expand the dialogue between theories of memory and Physical Education, in scientific productions and pedagogical interventions in the area.
\end{abstract}

KEYWORDS: Memory; Physical education; Academic production

Teorías de la memoria en la producción científica en Educación Física: un análisis en revistas brasileñas.

\title{
RESUMEN
}

El estudio analiza cómo surgen las concepciones de la Memoria en las producciones científicas de Educación Física en revistas brasileñas publicadas en el portal de publicaciones periódicas da Capes. Para ello, se seleccionaron producciones académicas publicadas en revistas indexadas, entre los años 2013 a 2019, con calificación Qualis Capes entre A1 y B2. Se analizaron quince artículos, agrupados en categorías según los temas cubiertos en los estudios. Los resultados presentan las concepciones de la memoria abordadas en las producciones, los objetivos, así como los aspectos metodológicos que se desarrollaron. Las consideraciones apuntan que necesita expandirse el diálogo entre las teorías de la memoria y la Educación Física, en producciones científicas e intervenciones pedagógicas en el área.

PALABRAS-CLAVE: Memoria; Educación física; Producción académica 


\section{INTRODUÇÃO}

As universidades públicas têm uma essencial função social na formação inicial e continuada de educadores, entre eles os professores de Educação Física, onde busca uma preparação coletiva para atuar no contexto das salas de aula e dar subsídios às condições mínimas que lhes permitam intervir na superação de propostas pedagógicas conservadoras.

Isso é uma demonstração de compromisso social que propõe superar o atual modelo de organização social e mobilizar um coletivo fortalecido para romper paradigmas, crenças e convicções previamente estabelecidas e segmentadas que discrimina as pessoas, o que é um desafio não só para as universidades públicas e para os professores de Educação Física, mas também para os demais membros da sociedade e da escola pública que acreditam na necessidade da mudança e da transformação social (CRUZ; BARBOSA NETO, 2010).

Assim, buscou-se apreender os temas, os objetos e as abordagens que estão sendo privilegiados na produção de conhecimento na Educação Física e seus possíveis diálogos com o campo teórico da Memória no Brasil. Nessa direção, como fonte de análise utilizou-se artigos científicos publicados em periódicos nacionais, veiculados em português e indexados ao Portal de Periódicos da Coordenação de Aperfeiçoamento de Pessoal de Nível Superior (Capes), base eletrônica de dados que se configura como uma biblioteca virtual que reúne e disponibiliza às instituições de ensino e pesquisa no Brasil produção científica nacional e internacional com vistas a reduzir o déficit e os desnivelamentos regionais no acesso à informação científica.

Nessa perspectiva, a atividade teórica por si só não se materializa, não sendo, pois, práxis. Por outro lado, a prática também não fala por si mesma, ou seja, teoria e prática são indissociáveis como práxis. Assim, destaca-se a importância da tríade ação-reflexão-ação, tendo em vista a necessidade de o docente refletir na e sobre sua prática, o que lhe permite construir os saberes necessários e as posturas crítico-reflexivas para uma atuação profissional qualificada.

Torna-se importante, desde a formação inicial, o entendimento de que o exercício docente exige investigação, pesquisa e reflexão sobre o ensinar e o aprender. Portanto, fazer uma reflexão sobre as teorias da memória e suas contribuições nas produções científicas e na prática docente em Educação Física, aproxima este professor com a área da educação. Sabe-se que a Educação Física como área acadêmica é permeada por debates e propostas imersas em diversos caminhos epistemológicos. Contudo, a discussão tratada neste trabalho, busca refletir a docência em Educação Física, no campo escolar, e propõe contribuições científicas para a fundamentação da proposta pedagógica do professor, a partir da aproximação com as concepções filosóficas e científicas da 
Memória. Assim, ser professor está intimamente relacionado ao ato de refletir sobre a ação, pois desta forma estaremos valorizando o saber, o fazer e o porquê fazer.

Assim, o objetivo deste estudo abrange a necessidade de identificar e analisar a discussão sobre as teorias da memória presente na produção científica da Educação Física, mais precisamente, as publicações nos periódicos brasileiros.

Compreende-se que ao analisar os artigos publicados nos periódicos nacionais, permite-nos debruçar na reflexão sobre como o campo da memória contribui para o desenvolvimento científico da Educação Física, isto torna necessário porque a posição que o professor e o pesquisador assume a esse respeito, tem repercussões imediatas em três âmbitos fundamentais da sua prática pedagógica: do trato com o conhecimento, da formação do pensamento teórico-científico dos alunos e da avaliação do seu rendimento. Também, porque o reflexo dessa prática pedagógica pode resultar na ampliação do espaço de contestação à função social da escola, ou no fortalecimento da reprodução do status quo, que determinam a forma e o conteúdo dessa instituição.

A prática profissional em Educação Física é um tema bastante estudado, produções científicas como teses de doutorado, dissertações de mestrado, artigos em periódicos, livros, entre outros trabalhos, apresentam-se em uma vasta bibliografia sobre o determinado assunto. Estudos como o de Betti; Et al (2011), Oliveira; Et al (2017), Pereira; Et al (2020), Castro; Et al (2017), apresentam como a produção acadêmica em Educação Física avançou nos últimos anos. No entanto, abordar uma problemática tão significativa parte da necessidade em realizar um trabalho socialmente útil partindo do acumulado cientificamente e propondo a superação de problemáticas, que por ventura, não tenham sido solucionadas.

Segundo Oliveira; Et al (2017), por sua vez, avalia a produção acadêmica na Educação, o qual apresenta que o a produção científica em Educação Física tem sido analisada sob diferentes aspectos, ou seja, levando em consideração questões como gênero, identidade, perfil, representações, formação docente, práticas docentes, saberes docentes, condições e relações de trabalho. No entanto, a área primordial das publicações acadêmicas em Educação Física é a Educação, ou seja, há uma predominância nos trabalhos que dialogam com as Ciências Humanas (OLIVEIRA; ET AL 2017).

Neste sentido, faz necessário refletir sobre o estudo da Memória e sua inserção nas produções em Educação Física, levando em consideração às determinações históricas, sócio-econômicas e políticas de uma sociedade capitalista em processo de reestruturação produtiva, buscando contribuir no debate sobre a necessidade de qualificação profisssional da área, no sentido da emancipação humana, algo que ainda não aprece nas produções científicas.

Portanto, ao discutir a Memória enquanto área do conhecimento e objeto multifocal do saber, é possível encontrar diversas abordagens teóricas reveladas em cada momento histórico da sociedade, 
as quais são desenvolvidas por vários estudiosos. Segundo Cordeiro (2015), os estudos sobre memória constituem-se, desde seu surgimento, na Grécia antiga como um problema filosófico, o que permanece até os dias de hoje dentro das discussões de diversas áreas do conhecimento como a psicologia, as neurociências cognitivas, a filosofia, a história e a sociologia, tornando-a um campo interdisciplinar de estudo com suas variadas dimensões. Podemos tomar como exemplo as dimensões da Memória nos estudos de Halbwachs. Segundo Halbwachs (2013), a memória é um processo de reconstrução e deve ser analisado considerando dois aspectos. O primeiro é o fato de não se tratar de uma repetição linear dos acontecimentos no contexto atual; e o segundo é se diferenciar dos acontecimentos que podem ser localizados em um tempo ou espaço que se envolve num conjunto de relações sociais. Para o autor, a lembrança advém das relações sociais desenvolvidas no cotidiano, sendo assim a memória individual só pode ser estabelecida a partir de memórias coletivas.

Mesmo diante deste cenário, a produção acadêmica em Educação Física, que dialogam com as teorias da Memória, buscam propor sugestões para uma saída desta crise, portanto contribuem significativamente como auxílio na formação e atuação de professores. Porém, ainda é necessário avançar na qualificação das produções, para que estas propostas se concretizem no cotidiano escolar, para assim reconfigurar, de forma eficiente, a práxis pedagógica dos professores.

A espiral contínua de ação-reflexão-ação contribui para a análise, compreensão e avaliação do processo educativo, pois “a reflexão envolve consciência crítica do professor sobre o próprio trabalho desenvolvido, apontando falhas e acertos no decorrer da caminhada, envolve também aceitação de si mesmo frente aos educandos" (COSTA, 2010, p. 20), fazendo com que o professor repense suas próprias ações.

Contemplar o objetivo traçado neste estudo, requer utilizar da Memória como área do conhecimento e uma fonte privilegiada de informação. Delgado (2006) assegura que tempo e memória constituem-se em elementos de um único processo, são pontos de ligação, elos de uma mesma corrente, que integram as múltiplas extensões da própria temporalidade em movimento. Desse modo, compreender, nesse contexto, como a literatura especializada no assunto traz o debate sobre a Memória nas produções em Educação Física, no país, constitui uma tarefa fundamental para a apreensão dos fatores e dos elementos que atravessam o aludido trabalho

A Memória, por sua vez, como suporte teórico e área de conhecimento científico, é um caminho possível para que sujeitos percorram a temporalidade que marca suas vidas. Tão logo, perceber como estas experiências implicam diretamente nas atividades cotidianas, bem como, supõe olhar com cuidado para essa Memória que preserva elementos da experiência coletiva, particular e individual. 


\section{DELINEAMENTO DO ESTUDO}

O presente trabalho caracteriza-se como um estudo de revisão sistemática, uma abordagem de estudo que recorre a fonte de dados já publicados sobre um tema em especial, assim busca selecionar, avaliar e caracterizar estudos e pesquisas, busca também identificar conceitos relevantes e analisa-los criticamente (SAMPAIO; MANCINI, 2007).

Assim sendo, buscou-se levantar o que é produzido e publicado nos periódicos brasileiros sobre as teorias da Memória e Educação Física, mais precisamente, como a Educação Física dialoga com o campo teórico da Memória nas produções acadêmicas da Área. A opção por buscar as produções em periódicos, se deve ao fato que estas produções são, em grande medida, mais representativas e estabelecem uma qualidade necessária para a análise. Tal método é bastante comum em estudos deste tipo, uma vez que os artigos selecionados para a análise possibilitam novas hipóteses, surgidas a partir das leituras criteriosas. Dessa forma o investigador tem um estudo em evolução constante, uma vez que seus pressupostos surgem apenas como uma iniciação para o tema, e ao desenvolver as leituras, buscam evitar a fuga do assunto proposto, entretanto novas ideias e possibilidades podem surgir à medida que a análise se desenvolve.

Os textos selecionados para ser objeto de análise deste estudo, foram publicados em periódicos indexados ao Portal de Periódicos da Capes (uma base eletrônica de dados que se configura como um repositório de produções científicas), estabelecemos como critério de inclusão os periódicos classificados com Qualis Capes entre A1 e B2 referentes a área da Educação Física

O recorte temporal para análise dos artigos compreendeu entre os anos de 2013 a 2019, a opção de tomar este período como recorte temporal tem relação ao fato que foi realizada a última avaliação de classificação de periódicos da Capes, quadriênio 2013 a 2016.

A seleção dos estudos, objeto da análise deste trabalho, foi realizada em duas fases. A primeira fase, foi feito um levantamento, a partir da ferramenta de busca do Portal de Periódicos da Capes, dos periódicos Nacionais cadastrados na área do conhecimento da Ciências da Saúde - Educação Física com a classificação do Qualis entre A1 e B2.

A segunda fase, foi feita uma busca dos artigos nos portais dos próprios periódicos. Conforme necessidade de reunir todos os estudos em língua portuguesa, publicados no período de 2013 a 2019, implicou-se o uso do descritor "Memória".

No caminhar do levantamento, buscou-se filtrar todos os artigos que tinham como tema a Memória e a Educação Física, além da leitura dos títulos dos artigos, realizamos a análise dos 
resumos e das palavras-chave. Ao selecionar os artigos que atendiam aos critérios de inclusão, foi realizada a leitura do artigo completo.

A revisão sistemática empreendida neste estudo propôs leituras minuciosas dos artigos, sustentando uma práxis que culmine com a identificação dos significados e sentidos conferidos às teorias da Memória e a Educação Física, identificou-se as abordagens metodológicas dos estudos, bem como as concepções e conceitos de Memória atribuídos nos artigos.

As proposições metodológicas utilizadas, desdobrou as análises nas categorias encontradas, no intuito de reconhecer suas semelhanças, diferenças, inter-relações, fundamentados nos referenciais abordados no texto.

\section{RESULTADOS E DISCUSSÕES}

A busca feita no Portal de Periódicos da Capes, conforme critérios estabelecidos para este trabalho, resultou em um total de 11 periódicos na área da Educação Física com classificação entre A1 e B2, porém em 05 periódicos não haviam artigos publicados, no recorte de tempo estabelecido, com o tema Teorias da Memória e Educação Física. Assim, a primeira busca emergiu 39 artigos em 06 periódicos. Após este primeiro levantamento, foi realizada a leitura dos resumos dos artigos com a finalidade de selecionar os textos que atendessem aos critérios propostos, bem como, que dialogassem com a categoria Teorias da Memória e Educação Física.

Este conjunto de procedimentos permitiu selecionar o total de 15 artigos que estabeleciam conexão direta com o tema proposto para a análise, Educação Física e as teorias da Memória.

\begin{tabular}{l|l|l}
\hline \multicolumn{2}{c}{ Quadro 01: Artigos e Periódicos } \\
\hline Periódico & $\begin{array}{l}\text { Qualis Capes } \\
\text { Educação Física }\end{array}$ & $\begin{array}{l}\text { Quantida } \\
\text { des de } \\
\text { Artigos }\end{array}$ \\
\hline Motrivivência: Revista de Educação Física, Esporte e Lazer & B2 & 02 \\
\hline Revista Pensar a Prática & B2 & 02 \\
\hline Revista Movimento & A2 & 06 \\
\hline Revista Brasileira de Ciências do Esporte & B1 & 02 \\
\hline Revista Brasileira de Ciência e Movimento & B2 & 01 \\
\hline Revista Brasileira de Educação Física e Esporte & B1 & 02 \\
\hline Total & & $\mathbf{1 5}$ \\
\hline
\end{tabular}


$\mathrm{Na}$ análise pormenorizada dos textos lidos na íntegra percebe-se a diversidade de temas envoltos nas publicações, nesse emaranhado, as concepções e conceitos de memória aparecem direta em alguns artigos, e em outros, justapostas a outras questões como por exemplo, a história dos centros de memória das universidades e a Capoeira como campo de estudos da memória social.

As categorias que emergiram na análise dos textos foram organizadas em três grupos: a) Prática Pedagógica do Professor de Educação Física; b) Elementos da Cultura Corporal, lutas, dança, esportes e capoeira; c) Centros de Memórias em Educação Física e Esportes;

\section{Prática Pedagógica do Professor de Educação Física}

A categoria Prática Pedagógica do Professor de Educação Física agrupa trabalhos que tem como temática o desenvolvimento da atividade profissional em Educação Física. Para isso, os autores lançam mão de diversos aspectos relacionados a esta questão, com distintos enfoques, olhares e trilhas diferenciadas.

Quadro 02: Prática Pedagógica do Professor de Educação Física

\begin{tabular}{|c|c|c|c|}
\hline Artigos & Autores & Periódico & Ano \\
\hline $\begin{array}{l}\text { Rotinas, estratégias e saberes de } \\
\text { professores de Educação Física: um } \\
\text { estudo de caso etnográfico }\end{array}$ & $\begin{array}{l}\text { Sanchotene, Molina } \\
\text { Neto }\end{array}$ & $\begin{array}{c}\text { Revista } \\
\text { Brasileira de } \\
\text { Educação } \\
\text { Física e Esporte }\end{array}$ & 2013 \\
\hline $\begin{array}{l}\text { A CONSTRUÇÃO DA MEMÓRIA EM } \\
\text { VIDA: a participação do professor } \\
\text { Germano Bayer na história da Educação } \\
\text { Física paranaense }\end{array}$ & $\begin{array}{l}\text { Ordonhes, Gianatti, } \\
\text { Pereir, Silva e Capraro }\end{array}$ & Motrivivência & 2016 \\
\hline $\begin{array}{c}\text { Arquivos pessoais de professores de } \\
\text { educação física: organização arquivística } \\
\text { e pesquisa histórica }\end{array}$ & $\begin{array}{l}\text { Linhales, Oliveira, } \\
\text { Santos e Camargo }\end{array}$ & $\begin{array}{l}\text { Revista } \\
\text { Brasileira de } \\
\text { Ciências do } \\
\text { Esporte }\end{array}$ & 2017 \\
\hline
\end{tabular}

Fonte: Elaboração Própria

Os artigos selecionados nesta categoria, a concepção de Memória aparece desarticulada com os estudos dos clássicos das teorias da memória, ou seja, os conceitos não dialogam com as concepções imbricadas em estudos da área. Oredenes, Et al (2016), destacam que a construção de 
uma memória para as ações didáticas em Educação Física, contribuem para uma edificação de uma memória pedagógica do referido componente curricular na escola. Diante disso, entende-se que a principal função da escola é a socialização do conhecimento, produzido historicamente e consolidado nos diversos conteúdos escolares, o que implica ao professor ter domínio destes conteúdos, bem como dos meios para torna-los acessíveis aos estudantes. Partimos da concepção de que as relações sociais humanas estruturadas ao longo da história interferem diretamente no trabalho pedagógico do professor em sala de aula, trabalho pedagógico este que deve objetivar a emancipação humana dos sujeitos envolvidos no processo.

Assim, precisamos compreender que “[...] a memória é uma evocação do passado. É a capacidade humana de reter e guardar o tempo que se foi, salvando-o da perda total" (CHAUÍ, 1995, p. 125). Sobre a noção de memória coletiva, Halbwachs - citado por Pollak (1989) - destaca diferentes pontos de referência que estruturam nossa memória e que a insere na memória da coletividade a que pertencemos.

Nas palavras de Linhales et al (2017), a memória permite identificar trajetórias distintas e questionar a presença dos sujeitos no próprio processo de organização do campo pedagógico e acadêmico da Educação Física. Portanto, a prática educativa é um ato político na medida em que as ações pedagógicas estão vinculadas a determinada concepção advinda das memórias entrelaçadas com as vivências pessoais do educador. Isso traduz a prática pedagógica em um determinado sentido, para que isso se torne realidade o professor deve ter consciência de suas responsabilidades como educador.

Sanchotene e Molina Neto (2013), toma o conceito de Memória a partir da teoria do Habitus com base em Bourdieu, busca compreender a constituição da prática pedagógica em Educação Física é desenvolvido pela internalização de um aprendizado pautado em saberes adquiridos no cotidiano da prática profissional.

Nesse sentido, Bourdieu (2011) destaca que o tempo possui uma natureza social e o que demonstra isso é a noção de Habitus, ou seja, um sistema de disposições incorporadas que define as ações de um agente. Sendo que os agentes sociais se diferenciam pelos gostos e hábitos que praticam, e é por intermédio destas práticas que se exprime ou se traduz a posição desses nas classificações sociais objetivas. A utilização de estratégias didáticas e pedagógicas é consolidado através da construção de narrativa e funciona como uma moeda de troca entre professores e estudantes, a partir da aquisição dos capitais econômico, cultural, social e simbólico.

Assim, considerando que os conhecimentos das teorias da memória podem contribuir efetivamente para o desenvolvimento da prática pedagógica em Educação Física, compreende-se a escola é uma instância privilegiada para o desenvolvimento humano. Saviani (1996) aproxima-se 
dessa visão ao entender que a atividade educativa é imprescindível para a transformação social com base na filosofia da práxis.

Deste modo, a atuação profissional em Educação Física assume a característica de inacabada, vinculada à história de vida dos sujeitos em permanente processo de formação, que proporciona a preparação profissional e o estabelecimento da identidade, esta por sua vez, se dará com o convívio do indivíduo nos mais variados espaços, bem como na busca pelo conhecimento e pela renovação de seus saberes.

\section{Elementos da Cultura Corporal, lutas, dança, esportes e capoeira}

Os artigos que compõem a categoria Elementos da Cultura Corporal, lutas dança, esportes e capoeira tratam, em alguma medida, não apenas a interpretações históricas sobre os conceitos dos elementos da Cultura Corporal, mas buscar discutir sobre o processo de construção de identidades, a partir da memória das práticas corporais tratadas nos artigos. Buscam, por meio de distintos referenciais e diversificada metodologia, problematizar as bases conceituais da Memória em diálogo com o tema específico de cada produção.

Os estudos analisados neste tópico, insere-se entre os que investigam as relações Educação Física, sociedade e Práxis Pedagógica. Especificamente buscam contribuir com respostas cientificas das problemáticas significativas correspondentes às experiências das práticas corporais que envolvem os elementos da Cultura Corporal. Analisam, especificamente, as propostas da de desenvolvimento e apreensão da cultura pelos sujeitos e quais as relações as concepções de Memória estabelecem entre os conhecimentos da Educação Física e a relação com a Memória.

Quadro 03: Elementos da Cultura Corporal, lutas, dança, esportes e capoeira

\begin{tabular}{|c|c|c|c|}
\hline $\begin{array}{c}\text { Artigos } \\
\end{array}$ & Autores & Periódico & Ano \\
\hline $\begin{array}{l}\text { O "Kung Fu" no Brasil na perspectiva } \\
\text { dos mestres pioneiros: problemas e } \\
\text { perspectivas no uso da história oral como } \\
\text { instrumental de análise }\end{array}$ & $\begin{array}{l}\text { Ferreira, Marchi Júnior, } \\
\text { Capraro. }\end{array}$ & $\begin{array}{c}\text { Revista } \\
\text { Brasileira de } \\
\text { Educação } \\
\text { Física e } \\
\text { Esportes }\end{array}$ & 2014 \\
\hline $\begin{array}{c}\text { Capoeira: a memória social construída } \\
\text { por meio do corpo }\end{array}$ & $\begin{array}{l}\text { Cunha, Vieira, Tavares, } \\
\text { Sampaio. }\end{array}$ & Movimento & 2014 \\
\hline $\begin{array}{c}\text { Estádio do Maracanã 1950-2010 na } \\
\text { memória de torcedores }\end{array}$ & Tavares e Votre & Movimento & 2014 \\
\hline $\begin{array}{c}\text { As origens do "vale-tudo" na cidade de } \\
\text { Curitiba-PR: memórias sobre identidade, } \\
\text { masculinidade e violência }\end{array}$ & $\begin{array}{l}\text { Passos, Prado, Júnior e } \\
\text { Caparo. }\end{array}$ & Movimento & 2014 \\
\hline
\end{tabular}




\begin{tabular}{c|c|c|c}
\hline $\begin{array}{c}\text { Narrativas de atletas de voleibol nos } \\
\text { jogos olímpicos } \\
\text { (1964 e 1968) }\end{array}$ & Carmona, Silva e Mazo & Pensar a Prática & 2015 \\
\hline $\begin{array}{c}\text { Fotografias do basquetebol na cidade do } \\
\text { Rio Grande/RS: memórias esportivas }\end{array}$ & França e Júnior & Pensar a Prática & 2016 \\
\hline $\begin{array}{c}\text { O percurso esportivo das mulheres } \\
\text { pioneiras no cenário Paralímpico Sul- } \\
\text { Rio-Grandense }\end{array}$ & Begossi e Mazo & $\begin{array}{c}\text { Revista } \\
\text { Brasileira de } \\
\text { Ciência e } \\
\text { Movimento }\end{array}$ & 2016 \\
\hline $\begin{array}{c}\text { Memórias e significados de dançar por } \\
\text { Muitos anos: o que nos dizem idosos que } \\
\text { dançaram ao longo da vida }\end{array}$ & Tolocka, Leme e Silva & Movimento & 2018 \\
\hline & & & \\
\hline
\end{tabular}

Fonte: Elaboração Própria

Para Ferreira; Marchi Júnior; Capraro (2014), a concepção de Memória abarca as tendências culturais que a memória está associada, ao indicar as ambivalências existentes no debate acerca da memória e história oral, os autores afirmam que a pesquisa não propõe dar respostas definitivas acerca da temática, pelo contrário, afirma que a aproximação com os pioneiros do Kung $\mathrm{Fu}$, permitiu a reflexão sobe os conflitos nas discussões de poder envolvendo a arte marcial.

Em Cunha et al (2014), a discussão sobre memória dialoga com a percepção da memória social como instrumento analítico e reflexivo, lança mão das discussões sobre memória social para compreender melhor os processos de formação de identidade da capoeira. O estudo discorre seu diálogo com a capoeira e a concepção de memória com base nas referências de Pierre Nora, onde traça o vínculo entre corporeidade e desenvolvimento da memória não apenas como uma base biológica, entende o corpo como um dos mais veículos de manifestação cultural da humanidade. Para os autores, o uso da memória constitui importante instrumento metodológico no sentido de incorporar a versão dos sujeitos que até então estavam desprivilegiados, marginalizados e alijados da história oficial. Tais processos guardam relação, entre outras coisas, com a desvalorização da memória, da experiência, das identidades, das territorialidades - uma questão que a história oral e os estudos da memória tentam reparar.

Ao identificar e analisar os significados das memórias de torcedores sobre o estádio Maracanã, Tavares e Votre (2014), utilizam o referencial teórico da abordagem psicossocial da memória, privilegiando os aspectos que contribuíram para a construção do estádio. Assim, a memória é conceituada como uma área do conhecimento permeada por intercessão de saberes, percepções e representações sociais. Desta forma, a abordagem do estudo destaca-se por debater a relação da memória com monumentos (lugares da memória), bem como o patrimônio arquitetônico (que nos acompanham por toda a vida), as paisagens, as datas e personagens históricos (de cuja importância 
somos incessantemente lembrados), as tradições, os costumes, as regras de interação, o folclore, a música, e até a culinária. É nesse contexto que a relação dos sujeitos e das coletividades sociais vividas na interação social, fazem parte da memória socialmente compartilhada, historicamente desenvolvida e coletivamente alimentada.

Passos et al (2014), desenvolvem o estudo com a concepção de memória nas representações sociais, assim os autores fundamentam sua análise acerca do desenho dessas narrativas a partir do conceito de identidade narrativa de Paul Ricoeur (2012), em que o sujeito ao significar o mundo faz uma hermenêutica de si, por meio da dialética entre mesmidade e ipseidade. A mesmidade como identidade percebida em si mesma, imutável no tempo, “idem”, ou seja, a mesma; já a ipseidade como identidade pessoal, reflexiva, marcada pela alteridade, pela ação e suas mudanças, esta relação leva o indivíduo a refletir sobre si apresentando isso através da narrativa de vida.

Ao analisar a reconstrução das memórias das participações dos atletas sul-riograndenses de voleibol nos Jogos Olímpicos de 1964 e 1968, estudo de Carmona, et al (2015), bem como França e Júnior (2016) ao explorar fontes fotográficas sobre o basquetebol na cidade de Rio Grade-RS para traçar as representações da memória na construção da identidade esportiva da cidade, utilizam o conceito de memória nas concepções de Halbwachs, portanto assegura que a memória coletiva reforça a coesão social, não pela coerção, mas pela adesão afetiva ao grupo. Fato que o leva a considerar a existência, via memória compartilhada por diferentes grupos sociais, de uma espécie de "comunidade afetiva". Essa ideia de comunidade afetiva supõe formas de convivência, interação e relacionamentos inclusive no tempo livre e de lazer em especial.

Ao abordar o percurso esportivo das atletas pioneiras no esporte Paralímpico no Rio Grande do Sul, Begossi e Matos (2016) acompanham o pensamento de Halbwachs nos pressupostos da memória coletiva. Porém, ao discorrer sobre memória coletiva, Pollak (1989) reconhece a memória como uma operação coletiva dos acontecimentos e das interpretações de experiências do passado que se quer salvaguardar e se integrar em tentativas mais ou menos conscientes de definir e de reforçar sentimentos de pertença social e o estabelecimento de fronteiras sociais entre coletividades diferentes. É, portanto, nesse sentido que a referência ao passado serve para manter a coesão dos grupos e das instituições que compõem uma sociedade, para definir seu lugar respectivo, sua complementariedade, mas também as oposições irredutíveis.

Para Tolocka, Leme e Silva (2018) identificar o significado e as memórias dos idosos praticantes de dança, recorreu ao conceito de memória na análise de Ricoeur, que considera que a manutenção de si deve ser feita baseada em uma conduta ética, na qual o indivíduo que narra se responsabiliza por sua conduta diante do outro. Dessa forma, Leme e Silva conclui que a narrativa desses idosos é construída pelo engajamento e compromisso com em suas atividades corporais, neste 
caso a dança, que, acredita nas contribuições que a dança traz e trouxe para o desenvolvimento de suas vidas. Concepções que podem refletir na reelaboração do habitus, conforme Bourdieu, enquanto memória inscrita nos corpos dos idosos que, ao desnaturalizar suas crenças e valores, exteriorizam estes novos habitus que disseminam entre outras pessoas práticas que rompem, em certa medida, com certos paradigmas da sociedade.

Sinteticamente, percebe-se nas produções uma abordagem de cunho metodológico, que amplia o conceito de memória no sentido de abarcar elementos que constituem as lembranças e os fragmentos da memória individual e da memória social. A diversidade de abordagens sobre as teorias da memória nas produções, exigiu um procedimento investigativo detalhado, para reconhecer as percepções de memória que os autores desenvolveram.

\section{Centros de Memórias em Educação Física e Esportes}

Os estudos da categoria Centros de Memórias em Educação Física e Esportes, reúne artigos que debatem sobre os Centros de Memórias e Esportes de Universidades públicas brasileiras, com o objetivo de identificar como estes espaços preservam, recuperam e guardam as memórias relacionadas aos cursos de Educação Física e práticas esportivas no geral. As universidades públicas têm uma essencial função social na formação inicial e continuada de profissionais de diversas áreas, entre eles os profissionais de Educação Física, onde busca uma preparação coletiva para atuar em diversos contextos e dar subsídios às condições mínimas que lhes permitam intervir na criticamente na sociedade.

Sendo assim, os trabalhos que compõem esta categoria objetivam analisar os fundamentos pedagógicos dos centros de Memória e Esportes das Universidades públicas tratadas nos textos, bem como sua relação com os debates acerca do perfil formativo do professor de Educação Física e sua relação com as memórias produzidas sobre o desenvolvimento profissional dos egressos dos seus respectivos cursos.

Quadro 04: Centros de Memórias em Educação Física e Esportes

\begin{tabular}{c|c|c|c}
\hline Artigos & Autores & Periódico & Ano \\
\hline $\begin{array}{c}\text { A preservação da memória estudantil } \\
\text { como proposta curricular dos cursos de } \\
\text { Educação Física: o caso do centro de } \\
\text { memória do Departamento de Educação } \\
\text { Física (CEMEDEF) da UFPR }\end{array}$ & Souza e Capraro & Movimento & 2013 \\
\hline $\begin{array}{c}\text { Reflexões acerca da disponibilização de } \\
\text { fontes históricas no CEMEDEF/UFPR }\end{array}$ & $\begin{array}{c}\text { Queiroz, Azevedo, } \\
\text { Zanlorenzi, Capraro, } \\
\text { Silva, Mezzadri e }\end{array}$ & Motrivivência & 2014 \\
& & & \\
\hline
\end{tabular}




\begin{tabular}{c|c|c|c}
\hline & Godoy & \\
\hline $\begin{array}{c}\text { Centros de memória da Educação Física } \\
\text { e esporte das universidades federais } \\
\text { brasileiras: preservar memórias para } \\
\text { reconstruir histórias }\end{array}$ & Macedo e Goellner & Movimento & 2019 \\
\hline & & & \\
\hline
\end{tabular}

Fonte: Elaboração Própria

Souza e Caparo (2013), apresentam como um centro de documentação em memória pode influenciar nas práticas formativas de um curso de Educação Física, parte especificamente de como a memória estudantil podem contribuir para formação acadêmica/profissional e contribuir para a formação de novos Centros de Memórias em outras universidades. Associa as bases epistemológicas da Educação Física com a concepção de memória fundamentada em Halbwachs, propões que a memória coletiva valoriza a prática educativa desenvolvida na formação em Educação Física e, consequentemente, contribui para o exercício profissional na área. Portanto, a trajetória da formação associadas às narrativas próprias deste percurso, fornecem subsídios sólidos para a atuação profissional.

Nesta mesma perspectiva, Queiroz et al. (2014), debate como a disponibilização de fontes históricas em um Cetro de Memória em Educação Física de uma Universidade Federal contribui para a realização de pesquisas sobre Educação Física e Memória. Situam a memória no lugar de destaque nas orientações dos trabalhos desenvolvidos no Cetro de Memória do Departamento de Educação Física da Universidade Federal do Paraná, e compreendem a concepção de Memória atribuída a Halbwachs, onde apoia a ideia da forma construtiva da memória social construída nas relações sociais, fruto das vivências em comunidade e referenciada em tempos e espaços produzidos culturalmente.

Dessa forma, os autores buscam perceber as narrativas disponibilizadas nas fontes histórias do Centro de Memória e compreender as perspectivas das pesquisas realizadas as fontes disponibilizadas no Centro.

As concepções de Memória que balizaram o estudo de Macedo e Goellner (2019), estão fundamentadas não suporte metodológico da história oral. Delgado (2006) assegura que tempo e memória constituem-se em elementos de um único processo, são pontos de ligação, elos de uma mesma corrente, que integram as múltiplas extensões da própria temporalidade em movimento, desta forma a proposta metodológica do estudo dialoga com uma espiral contínua de ação-reflexão-ação, contribui para a análise, compreensão e avaliação das ações dos Centros de Memória pesquisados e das narrativas dos atores sociais responsáveis pela preservação e reconstrução das memórias. 


\section{CONSIDERAÇÕES FINAIS}

A produção do conhecimento em Educação Física tem especificidades da área, no caso das produções analisas neste estudo, isso também se faz presente atribuindo identidade às contribuições das teorias da memória nas produções em Educação Física. Ao observar as produções, nota-se que é preciso que haja mudanças significativas no cenário pedagógico, social e político da Educação Física como área de conhecimento e intervenção. E diante dessa situação é indispensável a formatação de um aporte teórico com uma aproximação mais consubstanciada entre a Educação Física e as teorias da memória, pois as produções delataram que as teorias da memória contribuem significativamente para o avanço teórico-metodológico das pesquisas em Educação Física e Esportes.

A análise nos permitiu perceber quais os estudos que propõem o diálogo entre as teorias da memória e Educação Física. Constata-se que a relação de corresponsabilidade de memória e Educação Física, associadas as implicações que a prática pedagógica da Educação Física tem na contemporaneidade, desenvolvem influências positivas nas concepções de formação e desenvolvimento profissional da área.

O esforço deve apontar para a superação da situação atual da educação em que as normas e diretrizes cada vez mais apontam para ações inclusivas, e cada vez menos são criadas condições verdadeiras para garantir o acesso ao conhecimento qualificado e socialmente referenciado. Portanto, destacamos a relevância e a necessidade de um acúmulo teórico que apresente os subsídios para uma prática pedagógica coerente com uma Educação Física voltada para a emancipação humana, e a consolidação de uma sociedade comprometida em contemplar as verdadeiras demandas sociais, neste sentido as concepções das teorias da memória colaboram para a consolidação das finalidades educacionais da Educação Física, pois a reflexão que os aspectos conceituais da memória traz, implica em favor da historicidade, em determinada concepção de homem e sociedade que as intervenções pedagógicas podem formar. Isso tem relação com o fato de que a memória é um dos esteios das identidades, das singularidades e das particularidades de cada sujeito. São, portanto, suportes do ser no mundo - nos países, nos estados, nas cidades, nas comunidades rurais, nos guetos, nas ruas -, ou seja, são referenciais que tornam os homens e as mulheres sujeitos de seu tempo e de seu espaço, de maneira que não há como desligar ou aniquilar a relação entre o espaço e a memória, já que os dois se supõem.

Assim, a recente produção sobre o tema analisado inclui-se em um debate conceitual, o qual denuncia a demanda por revigoramento dos estudos, especialmente no que diz respeito à organização 
de alicerces para o desenvolvimento de uma determinada atividade pedagógica. Contudo, uma característica relevante das produções que se faz imprescindível frisar, é a pluralidade de questões temáticas tratadas nos textos, ainda assim destaca-se a necessidade de ampliar as produções, dada a relevância no processo de ampliação e divulgação das teorias da memória como subsídio para as produções científicas em Educação Física.

\section{REFERÊNCIAS}

BEGOSSI. Tuany Defaveri, MAZO. Janice Zarpellon. O PERCURSO ESPORTIVO DAS MULHERES PIONEIRAS NO CENÁRIO PARALÍMPICO SUL-RIO-GRANDENSE. Revista Brasileira de Ciência e Movimento, v. 24, n. 04, p. 143-155, 2016. Disponível em: https://portalrevistas.ucb.br/index.php/RBCM/article/view/6815. Acesso em: 10 Jun. 2019.

BOURDIEU, Pierre. A Economia das trocas simbólicas. 5. ed., São Paulo: Perspectiva, 2011.

BETTI, Mauro; FERRAZ, Osvaldo Luiz; DANTAS, Luiz Eduardo Pinto Basto Tourinho. EDUCAÇÃO FÍSICA ESCOLAR: estado da arte e direções futuras. Revista Brasileira de Educação Física e Esporte, v. 25, n. Spe, p. 105-115, 2011. Disponível em: https://www.scielo.br/pdf/rbefe/v25nspe/11.pdf. Acesso em 03 Jul. 2020.

CARMONA, Eduardo Klein; SILVA, Carolina Fernandes da; MAZO, Janice Zarpellon. NARRATIVAS DE ATLETAS DE VOLEIBOL NOS JOGOS OLÍMPICOS (1964 E 1968).

Pensar A Prática, [s.1.], v. 18, n. 4, p. 782-795, 17 dez. 2015. Disponível em: https://www.revistas.ufg.br/fef/article/view/33068. Acesso em: 13 de Jun. 2019.

CASTRO, Pedro Henrique Zubcich Caiado de; SILVA, Alan Camargo, SILVA, Luis Aureliano Imbiriba, LÜDORF, Sílvia Maria Agatti. A PRODUÇÃO CIENTÍFICA EM EDUCAÇÃO FÍSICA DE 2001 A 2010: caminhos da construção de um campo. Movimento (ESEFID/UFRGS), Porto Alegre, v. 23, n. 03. p. 869-882, 2017. Disponível em:

https://seer.ufrgs.br/Movimento/article/view/64610. Acesso em: 06 Jul. 2020.

CORDEIRO, Veridiana Domingos. Por uma sociologia da memória: análise e interpretação da teoria da memória coletiva de Maurice Halbwachs. Dissertação (Mestrado) - Faculdade de Filosofia, Letras e Ciências Humanas da Universidade de São Paulo, São Paulo, 2015.

COSTA, Edinara Scheffer. A importância da reflexão na formação de professores. 2010, $37 f$. Trabalho Monográfico de Conclusão de Curso (Licenciatura em Pedagogia) - Universidade Federal do Rio Grande do Sul, Porto Alegre, 2010.

CRUZ, Marlon Messias Santana. BARBOSA NETO, João Narciso. A relação dialética a educação inclusiva na atual conjuntura social. Lecturas EF y Deportes: revista digital. Buenos Aires, v. 14, n 131, 2009. Disponível em: http://www.efdeportes.com/efd131/a-relacao-dialetica-da-educacaoinclusiva-na-atual-conjuntura-social.html Acesso em 07 Jul 2020.

CUNHA, Igor Márcio Corrêa Fernandes da; VIEIRA, Luiz Renato; TAVARES, Luiz Carlos Vieira; SAMPAIO, Tânia Mara Vieira. CAPOEIRA: a memória social construída por meio do corpo. 
Movimento (ESEFID/UFRGS), [s.1.], v. 20, n. 2, p. 735-755, 19 fev. 2014. Disponível em: https://seer.ufrgs.br/Movimento/article/view/42052. Acesso em: 13 de jun. 2019.

DELGADO, Lucília de Almeida Neves.História oral e narrativa: tempo, memória e identidades.

História Oral, v. 6, p. 9-25. 2003. Disponível em:

https://revista.historiaoral.org.br/index.php?journal $=$ rho\&page $=$ article \&op $=$ view\&path $\% 5 \mathrm{~B} \% 5 \mathrm{D}=6$ 2\&path $\% 5 \mathrm{~B} \% 5 \mathrm{D}=54$. Acesso em 17 de agosto de 2019.

FERREIRA, Fernando Dandoro Castilho; MARCHI JÚNIOR, Wanderley; CAPRARO, André Mendes. O: problemas e perspectivas no uso da história oral como instrumental de análise. Revista Brasileira de Educação Física e Esporte, [s.1.], v. 28, n. 1, p. 65-76, mar. 2014. Disponível em: https://www.revistas.usp.br/rbefe/article/view/80780 Acesso em; 13 de Jun. 2019.

FRANÇA, Mateus Trevisan; MARCHI JÚNIOR, Wanderley. FOTOGRAFIAS DO BASQUETEBOL NA CIDADE DO RIO GRANDE/RS: memórias esportivas. Pensar A Prática, [s.1.], v. 19, n. 3, p. 506-521, 30 set. 2016. Disponível em:

https://www.revistas.ufg.br/fef/article/view/33737. Acesso em: 13 de jun. 2019.

HALBWACHS, Maurice. A memória coletiva. Tradução de Beatriz Sidou. $2^{\mathrm{a}}$ ed. São Paulo: Centauro, 2013.

LINHALES, Meily Assbú; OLIVEIRA, Thaís Nodare de; SANTOS, Fernanda Cristina dos; CAMARGO, Nájela Paula Tavares. Arquivos pessoais de professores de educação física: organização arquivística e pesquisa histórica. Revista Brasileira de Ciências do Esporte, [s.1.], v. 39, n. 3, p. 276-283, jul. 2017. Disponível em: http://www.rbceonline.org.br/pt-arquivos-pessoaisprofessores-educao-fsica-articulo-resumen-S0101328916301822. Acesso em 17 jun. 2019.

MACEDO, Christiane Garcia; GOELLNER, Silvana Vilodre. CENTROS DE MEMÓRIA DA EDUCAÇÃO FÍSICA E ESPORTE DAS UNIVERSIDADES FEDERAIS BRASILEIRAS: preservar memórias para reconstruir histórias. Movimento (ESEFID/UFRGS), [s.1.], v. 25, p. 0113, 14 jun. 2019. Disponível em: https://seer.ufrgs.br/Movimento/article/view/87769. Acesso em: 11 de Jun. 2019.

OLIVEIRA, Rogério Cruz de; RIGONI, Ana Carolina Capellini; TIRINTAN, Marilia Merle; SILVA, Wesley Marques; FERREIRA, Rosana Almeida; VELOZO, Emerson Luís; SILVA, Cinthia Lopes. PRODUÇÃO CIENTÍFICA EM EDUCAÇÃO FÍSICA E CULTURA: revisão sistemática. SALUSVITA, Bauru, v. 36, n. 2, p. 509-532, 2017. Disponível em: https://secure.unisagrado.edu.br/static/biblioteca/salusvita/salusvita v36 n2 2017 art 11.pdf. Acesso em 03 Jul. 2020.

ORDONHES, Mayara Torres; GIANATTI, Bianca Gutierrez; PEREIRA, Bruna Opieco; SILVA, Camila Gomes; CAPRARO, André Mendes. A construção da memória em vida: a participação do professor Germano Bayer na história da educação física paranaense. Motrivivência, [s.1.], v. 28, n. 48, p. 376-385, 21 set. 2016. Disponível em:

https://periodicos.ufsc.br/index.php/motrivivencia/article/view/2175-8042.2016v28n48p376.

Acesso em: 15 jun. 2019.

PASSOS, Daniella de Alencar; PRADO, Rodrigo Cribari; MARCHI JÚNIOR, Wanderley; CAPRARO, André Mendes. AS ORIGENS DO "VALE-TUDO" NA CIDADE DE CURITIBAPR: memórias sobre identidade, masculinidade e violência. Movimento (ESEFID/UFRGS), [s.1.], 
v. 20, n. 3, p. 1153-1173, 6 jul. 2014. Disponível em:

https://seer.ufrgs.br/Movimento/article/view/42829. Acesso em: 10 de Jun. 2019.

PEREIRA, Claudia Catarino; CARNEIRO, Fernando Henrique Silva, REIS, Nadson Santana, ATHAYDE, Pedro Fernando Avalone, MASCARENHAS, Fernando. O financiamento do esporte no periodismo científico brasileiro: uma revisão sistemática. Motrivivência, Florianópolis, v. 32, n. 62, p. 01-22, 2020.Disponível em:

https://periodicos.ufsc.br/index.php/motrivivencia/article/view/2175-8042.2020e64906. Acesso em: 03 Jul. 2020.

POLLAK, Michael. Memória, Esquecimento, Silêncio. Revista Estudos Históricos, Rio de Janeiro, v. 2, n. 3, p. 03-15, 1989. Disponível em:

http://bibliotecadigital.fgv.br/ojs/index.php/reh/article/view/2278/1417. Acesso em 27 de Junho de 2019.

SAMPAIO, Rosana Ferreira; MANCINI, Marisa Cotta. Estudos de revisão sistemática: um guia para síntese criteriosa da evidência científica. Revista Brasileira de Fisioterapia, [s.1.], v. 11, n. 1, p. 83-89, fev. 2007. Disponível em:

https://www.scielo.br/scielo.php?script=sci arttext\&pid=S1413-

35552007000100013\&lng=pt\&nrm=iso\&tlng=pt. Acesso em: 12 de Junho de 2019.

SANCHOTENE, Mônica Urroz; MOLINA NETO, Vicente. Rotinas, estratégias e saberes de professores de Educação Física um estudo de caso etnográfico. Revista Brasileira de Educação Física e Esporte, [s.1.], v. 27, n. 3, p. 447-458, set. 2013. Disponível em: https://www.revistas.usp.br/rbefe/article/view/63115. Acesso em 17 jun. 2019.

SOUZA, Elyandra Caroline Alves de; CAPRARO, Andre Mendes. A PRESERVAÇÃO DA MEMÓRIA ESTUDANTIL COMO PROPOSTA CURRICULAR DOS CURSOS DE EDUCAÇÃO FÍSICA: o caso do centro de memória do departamento de educação física (CEMEDEF) da UFPR. Movimento (ESEFID/UFRGS), [s.1.], v. 19, n. 3, p. 235-255, 16 jan. 2013. Disponível em: https://seer.ufrgs.br/Movimento/article/view/26735 . Acesso em: 11 de Jun. 2019.

TAFFAREL, Celi Zulke. ESCOBAR, Micheli Ortega. Mas, afinal, o que é Educação Física: reafirmando o marxismo contra o simplismo intelectual. In: Rascunho Digital, 2007. Disponível em: http://www.faced.ufba.br/rascunho digital. Acesso em 15 jan 2020.

TAVARES, Ana Beatriz Correia de Oliveira; VOTRE, Sebastião Josué. ESTADIO DO MARACANÃ NA MEMÓRIA DE SEUS FREQUENTADORES. Movimento (ESEFID/UFRGS), [s.1.], v. 20, n. 3, p. 1017-1038, 14 maio 2014. Disponível em: https://seer.ufrgs.br/Movimento/article/view/43624. Acesso em 13 de jun 2019.

TOLOCKA, Rute Estanislava; LEME, Lia Carla Gordon; SILVA, Valquiria Maria Tolocka Gomes da. MEMÓRIAS E SIGNIFICADOS DE DANÇAR POR MUITOS ANOS: o que nos dizem idosos que dançaram ao longo da vida. Movimento (ESEFID/UFRGS), [s.1.], v. 24, n. 4, p. 1281-1294, 6 jan. 2019. Disponível em: https://seer.ufrgs.br/Movimento/article/view/74922. Acesso em: 14 de Jun. 2019.

QUEIROZ, Kauê Fabiano da S.; AZEVEDO, Paola Caroline Silva; ZANLORENZI, Tiago Dimitrow; CAPRARO, André Mendes; SILVA, Marcelo Moraes e; MEZZADRI, Fernando 
Marinho; GODOY, Letícia. Reflexões acerca da disponibilização de fontes históricas no CEMEDEF/UFPR. Motrivivência, [s.1.], v. 26, n. 42, p. 250-258, 16 jun. 2014. Disponível em: https://periodicos.ufsc.br/index.php/motrivivencia/article/view/28674. Acesso em: 11 de Jun. 2019.

\section{NOTAS DE AUTOR}

AGRADECIMENTOS - Não se aplica.

CONTRIBUIÇÃO DE AUTORIA - Não se aplica.

FINANCIAMENTO - Não se aplica.

CONSENTIMENTO DE USO DE IMAGEM - Não se aplica.

APROVAÇÃO DE COMITÊ DE ÉTICA EM PESQUISA - Não se aplica.

CONFLITO DE INTERESSES - Não há conflito de interesses.

\section{LICENÇA DE USO}

Os autores cedem à Motrivivência - ISSN 2175-8042 os direitos exclusivos de primeira publicação, com o trabalho simultaneamente licenciado sob a Licença Creative Commons Attribution Non-Comercial ShareAlike (CC BY-NC SA) 4.0 International. Esta licença permite que terceiros remixem, adaptem e criem a partir do trabalho publicado, desde que para fins não comerciais, atribuindo o devido crédito de autoria e publicação inicial neste periódico desde que adotem a mesma licença, compartilhar igual. Os autores têm autorização para assumir contratos adicionais separadamente, para distribuição não exclusiva da versão do trabalho publicada neste periódico (ex.: publicar em repositório institucional, em site pessoal, publicar uma tradução, ou como capítulo de livro), com reconhecimento de autoria e publicação inicial neste periódico, desde que para fins não comerciais e compartilhar com a mesma licença.

\section{PUBLISHER}

Universidade Federal de Santa Catarina. Programa de Pós-Graduação em Educação Física. LaboMídia - Laboratório e Observatório da Mídia Esportiva. Publicado no Portal de Periódicos UFSC. As ideias expressadas neste artigo são de responsabilidade de seus autores, não representando, necessariamente, a opinião dos editores ou da universidade.

\section{EDITORES}

Mauricio Roberto da Silva, Giovani De Lorenzi Pires, Rogério Santos Pereira.

\section{HISTÓRICO}

Recebido em: 23 de abril de 2020.

Aprovado em: 22 de julho 2020. 